\title{
Aspectos Genéticos, Influência do Eixo GH/IGF1 e Novas Possibilidades Terapêuticas na Osteoporose Idiopática
}

\section{Genetics Aspects, GH/IGF1 Axis Influence and Advance Therapeutic Alternatives in Idiopathic Osteoporosis}

\author{
Renata Francioni Lopes ${ }^{(1)}$, Maria Lucia Fleiuss de Farias ${ }^{(2)}$
}

\section{RESUMO}

A osteoporose idiopática é uma condição rara que afeta ambos os sexos, mulheres durante o menacme e homens antes dos 65 anos. O diagnóstico somente pode ser considerado depois de serem descartadas todas as causas conhecidas de osteoporose. A apresentação clínica é heterogênea, variando desde o achado de osteoporose à densitometria em paciente pouco sintomático até múltiplas fraturas por fragilidade, principalmente de corpos vertebrais. A remodelação óssea encontra-se geralmente no limite inferior da normalidade, mas a reabsorção óssea sempre excede a formação, resultando em perda óssea. A disfunção osteoblástica, descrita na maioria dos artigos, tem sido relacionada a baixas concentrações do fator de crescimento insulina-simile (IGF-1) no sangue e na matriz óssea. Fatores genéticos e hormonais parecem envolvidos na etiopatogenia. Drogas anti-reabsortivas, como os bisfosfonatos, são úteis em reduzir a taxa de fraturas. Drogas anabólicas, tais como o hormônio de crescimento, o IGF-1 e mais recentemente a teriparatida (PTH recombinante), são mais promissoras, uma vez que elas realmente aumentam a massa óssea e melhoram a qualidade do osso. A proposta deste artigo é rever aspectos da fisiopatologia da osteoporose idiopática, rotina diagnóstica e alternativas terapêuticas.

Palavras-chave: osteoporose idiopática, eixo GH/IGF1, tratamento.

\section{INTRODUÇÃO}

A osteoporose idiopática é uma condição rara que acomete ambos os sexos. Só pode ser assim definida nas mulheres no menacme e homens até 65 anos após exclusão de todas as causas potencialmente conhecidas de osteoporo$\mathrm{se}^{(1)}$. Um melhor entendimento da genética da osteoporose idiopática, do papel do eixo GH/IGFl, da apresentação clínica heterogênea, assim como das alternativas terapêuticas vigentes será abordado a seguir.

\section{FATORES GENÉTICOS NA OSTEOPOROSE IDIOPÁTICA}

A fisiopatologia da osteoporose idiopática permanece

\begin{abstract}
Idiopathic osteoporosis is a rare condition that affects both sexes, women during menacme and men before 65 years. The diagnosis can only be considered after all known causes of osteoporosis are discarded. The clinical presentation is heterogeneous, ranging from densitometric finding in a patient with few symptoms to multiple fragility fractures, mainly vertebral. Bone turnover is usually in the low-normal range, but bone resorption always exceeds formation, resulting in net bone loss. The osteoblastic dysfunction, described in almost all papers, has been related to low insulin growth factor-1 (IGF-1) concentrations in blood and bone matrix. Genetic and hormonal factors seem to be involved. Antiresorptive drugs, such as bisphosphonates, are useful in reducing fracture rate. Anabolic drugs, such as growth hormone, IGF-1 and more recently teriparatide (recombinant PTH) are more promising, as they actually increase bone mass and improve bone quality. The purpose of this article is to review pathophysiologic aspects of idiopathic osteoporosis, diagnostic routine and therapeutic alternatives.
\end{abstract}

Keywords: Idiopathic osteoporosis, GH/IGF-1 axis, treatment.

obscura, mas os estudos sugerem que a diminuição do pico de massa óssea seja o principal determinante desta condição predominantemente hereditária ${ }^{(2-5)}$. O pico de massa óssea é definido como a máxima densidade mineral óssea atingida durante o crescimento e desenvolvimento, em conjunto com uma consolidação subseqüente que continua durante a fase de adulto jovem ${ }^{(5)}$. É aceito que a densidade mineral óssea máxima esteja presente durante a terceira ou quarta década de vida. Estima-se que mais de 60\% da massa óssea adulta esteja relacionada ao pico adquirido. $\mathrm{O}$ componente hereditário do pico de massa óssea tem sido estimado em torno de $50 \%$ a $70 \%$.

A densidade óssea exibe um padrão familiar em indiví-

Disciplina de Endocrinologia, Departamento de Clínica Médica, Hospital Universitário Clementino Fraga Filho (HUCFF) da Universidade Federal do Rio de Janeiro (UFRJ). Recebido em 10/08/05. Aprovado, após revisão, em 22/01/06.

1. Mestre em Endocrinologia pela UFRI

2. Doutora em Endocrinologia, coordenadora adjunta do Programa de Pós-Graduação em Endocrinologia pela UFRJ.

Endereço para correspondência: Renata Francioni Lopes, Rua Passo da Pátria 105/101, São Domingos, Niterói, CEP 24210-240, RJ, Brasil,

e-mail: renfrancioni@zipmail.com.br 
duos normais. Parece existir maior concordância na densidade mineral óssea de gêmeos monozigóticos que dizigóti$\cos ^{(6)}$. O caráter familiar da densidade óssea é adquirido bem precocemente, e a densidade óssea de meninas pré-púberes está correlacionada com a de suas mães ${ }^{(4)}$. Acredita-se que o pico de massa óssea seja fortemente influenciado pela hereditariedade, apesar de efeitos cumulativos do estilo de vida interferirem. Recentemente, foi descrita a relação do pico de massa óssea com o cromossomo llq 12-13, numa população de irmãs gêmeas saudáveis ${ }^{(3)}$.

A osteoporose é geralmente considerada doença poligênica desencadeada pela interação de alelos polimórficos comuns com fatores ambientais múltiplos ${ }^{(7)}$. Vários genes tem sido relacionados, como o gene do IGF-1, o gene do receptor da vitamina $\mathrm{D}$ (VDR), o gene do colágeno tipo I alfa l ( Col I $\alpha$ l), o gene do receptor estrogênico, o gene da esclerosteose e o promotor do gene da osteoprotegerina.

\section{GENE DO IGF-1}

Um dos melhores estudos de genes candidatos continua a ser o de Rotterdam, que apresentou evidências convincentes da associação alélica entre polimorfismos na região promotora do gene IGF- 1 e potencial risco de fratura. O estudo incluiu 7012 participantes e é um dos maiores estudos de associação realizados na área de metabolismo ósseo ${ }^{(8)}$. O gene do fator de crescimento semelhante à insulina (IGF-1) exerce efeitos anabólicos no osso. Pacientes com osteoporose idiopática têm um alto grau de polimorfismo no gene do IGF1, sendo evidenciada a associação de baixos níveis séricos de IGFl e homozigose para um alelo específico do microsatélite do gene de IGF1 - 192/192(9).

\section{GENE DO RECEPTOR DA VITAMINA D (VDR)}

Polimorfismos no gene que codifica o receptor de vitamina D (VDR) podem em parte justificar variações genéticas na massa óssea ${ }^{(10,11)}$. Sainz et al ${ }^{11)}$ estudaram uma população geneticamente homogênea de crianças apontando que polimorfismos no receptor da vitamina D estão relacionados a diferenças significativas ( $>1$ desvio padrão) na densidade óssea vertebral e femural entre genótipos de homozigotos recessivos (aa, bb) e dominantes (AA, BB). Esse estudo sugere que o genótipo pode ser de grande importância na previsão da densidade óssea antes que fatores etários e hormonais afetem a massa óssea ${ }^{(11)}$. Estudos em adultos e crianças sugerem que o efeito da ingestão de cálcio na densidade óssea depende do genótipo do receptor de vitamina D. Assim, a genotipagem do receptor de vitamina $\mathrm{D}$ pode ser útil na previsão dos reais benefícios da suplementação de cálcio(12).

\section{GENE DO COLÁGENO TIPO I $\alpha 1$ (COL $I \alpha 1)$}

Polimorfismos no gene do colágeno tipo I $\alpha$ l (col I $\alpha$ l) estão associados à diminuição da densidade óssea da coluna em crianças pré-puberais com genótipos recessivos homozigóticos e heterozigóticos comparados com o genótipo dominante, dados também encontrados em adultos ${ }^{(13)}$. Em homens com osteoporose idiopática também foi achado polimorfismo, existindo uma alta prevalência do alelo s e do genótipo SS sem relação com parâmetros do metabolismo ósseo, tais como osteocalcina, 25 hidroxivitamina D e paratormônio ${ }^{(14)}$.

\section{GENE DO RECEPTOR ESTROGÊNICO}

A importância do estrogênio para a maturação e a densidade óssea em ambos os sexos sugere que polimorfismos no gene do receptor do hormônio podem influenciar a densidade óssea, e não só os níveis séricos de estradiol. Uma área de restrição $(\mathrm{XbaI})$ do gene do receptor de estrogênio tem sido encontrada em casos de diminuição da densidade óssea em adolescentes do sexo masculino e mulheres jovens pré-menopausa $^{(15,16)}$.

\section{OUTROS GENES}

Mais recentemente, potenciais reguladores da densidade mineral óssea surgiram, como o gene da esclerosteose $(\mathrm{SOST})^{(17)}$ e o promotor do gene da osteoprotegerina (OPG), esta última considerada fundamental para o controle do processo de remodelação óssea ${ }^{(18)}$.

\section{EIXO GH/IGF 1}

Considerando a importância dos polimorfismos no gene do IGFl na fisiopatologia da osteoporose dita idiopática, uma melhor compreensão do papel do eixo GH/IGF1 no metabolismo ósseo se faz necessária.

O hormônio de crescimento (GH) é o principal regulador fisiológico da produção hepática de IGFl. Indivíduos deficientes de $\mathrm{GH}$ possuem baixos níveis de IGFl sérico e menor massa óssea que os normais ${ }^{(19)}$, e o declínio de IGFl sérico parece associado à redução de massa óssea no envelhecimento $^{(20)}$. Esses trabalhos apontam para um importante papel do IGFl circulante na aquisição do pico de massa óssea e na homeostase esquelética do indivíduo adulto. Entretanto, não parece haver defeito na secreção do GH nos homens com osteoporose idiopática, como constatado por 
Kurland et $a^{(21)}$. Estes autores avaliaram 14 homens com osteoporose idiopática após teste de estímulo com arginina e L-dopa, encontrando um padrão secretório normal do GH, apesar de níveis séricos de IGFl baixos, demonstrando que estes homens não eram deficientes de GH.

Por outro lado, existe relação entre IGFl sérico e o conteúdo esquelético de IGFl, ou seja, a quantidade de IGFl no microambiente ósseo depende da produção local de IGF1 pelos osteoblastos corticais e trabeculares e também do IGFl circulante. De fato, o maior reservatório de IGFs no organismo não é o fígado, mas sim o osso (especialmente IGF1 e IGF2). Nos casos de osteoporose idiopática, a contribuição esquelética parece diminuída ${ }^{(22)}$, contribuindo para os baixos níveis circulantes de IGFl.

Anormalidades na formação óssea em várias formas de osteopenia resultam do menor recrutamento ou de apoptose precoce das células osteoblásticas. Estas anormalidades estão associadas com alterações na expressão ou produção de vários fatores de crescimento, inclusive IGFs, que modulam a proliferação e a atividade das células de formação óssea ${ }^{(23)}$. Estudos in vitro demonstram a rápida apoptose dos osteoblastos na ausência de insulina e fatores de crescimento, inclusive os IGFs, além do envolvimento do receptor de IGF tipol nesta resposta. Sugerem ainda que a sobrevida dos osteoblastos é promovida por fatores de crescimento seqüestrados na matriz óssea, tendo o IGFl liberado na matriz óssea papel de recrutar novos osteoblastos para a superfície de remodelação ${ }^{(24)}$.

A formação óssea encontra-se alterada na osteoporose idiopática e a redução do IGFl intra-ósseo, em conseqüência de polimorfismos no gene do IGFl, que estaria associada à disfunção osteoblástica ${ }^{(25)}$.

O perfeito acoplamento dos processos de formaçãoreabsorção é necessário para a manutenção de um esqueleto saudável. O IGFl também parece interferir indiretamente nesse processo mediante seus efeitos, comprovados in vitro e in vivo, regulando a osteoprotegerina ${ }^{(26)}$. A osteoprotegerina é um peptídeo solúvel secretado pelas células pré-osteoblásticas, cuja função é ligar-se a um peptídeo de superfície no osteoblasto (RANKL), assim inibindo o contato do RANKL com o seu verdadeiro receptor no osteoclasto (RANK), inibindo o processo de ativação do osteoclasto e a subseqüente reabsorção óssea. Assim, o sistema RANKL/OPG/RANK está envolvido na dinâmica da remodelação óssea e constitui uma via crítica no esquema de interação osteoblasto - osteoclasto, com significativa relevância em terapêuticas futuras.

\section{APRESENTAÇÃO CLÍNICA DA OSTEOPOROSE IDIOPÁTICA}

Sua apresentação clínica é heterogênea variando de mero achado densitométrico em paciente pouco sintomático a múltiplas fraturas, habitualmente vertebrais ${ }^{(1,25)}$. Pode ser classificada como juvenil ou do adulto jovem. A doença, quando se inicia na infância, tende a melhorar com a puberdade, ocasião em que as fraturas patológicas cessam. Geralmente o quadro é silencioso até haver fratura, desencadeando uma dor aguda que pode persistir de 3 a 6 meses. Sucessivas fraturas vertebrais podem levar a um aumento da cifose torácica, perda de altura e até compressão radicular. No entanto, não ocorrem sintomas na maioria das microfraturas vertebrais. Como em todos os casos de osteoporose, $\mathrm{o}$ surgimento de uma fratura já evidencia grande redução na qualidade e na resistência óssea, e está associado ao aumento do risco de novas fraturas ${ }^{(27)}$. Assim, é fundamental que se tomem medidas preventivas no momento do diagnóstico da osteoporose.

A osteoporose é considerada idiopática depois de afastadas todas as causas potencialmente conhecidas. $\mathrm{Na}$ anamnese deve-se pesquisar a história reprodutiva, menopausa precoce, sintomas de hipogonadismo em homens, padrão nutricional, história de cálculo renal, imobilização, alcoolismo ou tabagismo e uso crônico de corticóide e anticonvulsivante. Outras causas secundárias, como doença tireoideana, síndrome de Cushing, hiperparatiroidismo primário, hiperprolactinemia, doença hepática ou gastrointestinal, doenças do tecido conjuntivo (que muitas vezes demandam uso crônico de corticóides), osteogenesis imperfecta, anorexia nervosa e doenças malignas (principalmente mieloma múltiplo) também devem ser afastadas ${ }^{(28)}$.

\section{DIAGNÓSTICO POR IMAGEM}

Radiografias simples têm baixa sensibilidade diagnóstica só detectando alterações quando a perda óssea excede $30 \%$, também não são úteis para acompanhar a evolução e os efeitos do tratamento. Podem levar à suspeita de hiperparatiroidismo e outras doenças que comprometam o osso e acarretam a osteoporose, mas sua maior utilidade é a detecção de fraturas. Especialmente a radiografia simples da coluna toracolombar permite observar osteófitos, calcificações da aorta abdominal, colapsos vertebrais (que falsamente elevam o valor da densidade mineral óssea à densitometria óssea), ainda estabelecendo o grau de deformidade dos corpos vertebrais e de toda a coluna, que leva ao desequilíbrio postural e à dor.

A densitometria óssea utilizando dupla fonte de RX é o 
método mais usado para quantificar a massa óssea. Mede-se a quantidade de mineral ósseo (gramas de cálcio por $\mathrm{cm}^{2}$ ) em áreas mais propensas a fraturas osteoporóticas: coluna lombar e fềmur proximal (colo, trocânter e fềmur total). $\mathrm{O}$ diagnóstico de osteopenia/osteoporose à densitometria é baseado em critérios definidos pela Organização Mundial de Saúde (OMS), mediante a comparação da densidade óssea do paciente com os valores do pico de massa óssea para o mesmo sexo (T-escore). Assim, considera-se haver osteopenia quando o T-escore fica entre $<-1$ até $-2,5$ desvios e osteoporose quando o T-escore é $\leq-2,5$ desvios abaixo dos valores médios obtidos em jovens. Estes valores são válidos para homens $\mathrm{e}$ mulheres ${ }^{(29)}$. Para cada desvio negativo, considera-se que o risco de fraturas dobre. Além disso, considera-se osteoporose grave uma densidade menor que $-2,5 \mathrm{DP}$ associada à fratura $^{(27)}$. A densidade óssea também é comparada com os valores esperados para população do mesmo sexo, idade, índice de massa corpórea ou etnia (Z-escore).

Em crianças e adolescentes recomenda-se avaliar a coluna lombar e corpo inteiro e apenas valorizar o Z-escore, uma vez que eles ainda não atingiram o pico de massa óssea. Qualquer redução na aquisição de osso ou perda óssea nesta faixa etária deve ser investigada, já que habitualmente, nessa etapa da vida, prevalece a formação óssea.

A história de osteoporose em familiares, principalmente de primeiro grau, é comum entre os pacientes com osteoporose idiopática, tanto homens ${ }^{(30)}$ quanto mulheres ${ }^{(31)}$. Assim, o risco de osteoporose no jovem é maior quando o pai do paciente masculino ou a mãe da paciente feminina teve osteoporose na juventude. Como raramente solicitase densitometria óssea em adolescentes e adultos jovens, mesmo com história familiar positiva, muitos casos de osteoporose idiopática podem estar sendo tardiamente diagnosticados, ou seja, somente no momento de manifestações clínicas como dores ósseas, múltiplas fraturas e/ou deformidades esqueléticas.

\section{DIAGNÓSTICO LABORATORIAL}

Não há anormalidade bioquímica característica nos pacientes com osteoporose idiopática. Apenas para afastar causas secundárias, a avaliação laboratorial inicial deve incluir dosagens sangüíneas de cálcio, fósforo, fosfatase alcalina, hemograma, eletroforese de proteínas, uréia, creatinina, função tireoideana, cortisol livre urinário das $24 \mathrm{~h} \mathrm{e} /$ ou teste de supressão noturna com $01 \mathrm{mg}$ de dexametasona (se há suspeita de Cushing), PTH (para afastar hiperparatiroidismo), IGFl e até teste de estímulo com insulina-hormônio de crescimento (se há suspeita de deficiência de $\mathrm{GH}$ ), prolactina e avaliação da função gonadal (testosterona em homens, estradiol e FSH durante a fase folicular nas mulheres).

$\mathrm{Na}$ osteoporose idiopática, a remodelação óssea é variada. Homens com osteoporose idiopática podem apresentar exacerbada reabsorção óssea, com aumento da excreção urinária de deoxipiridinolina e do peptídeo carboxiterminal do colágeno tipo I (CTX), associado a baixos níveis séricos de estradiol e testosterona livre, com SHBG (globulina de ligação dos hormônios sexuais) aumentada tendo correlação positiva com piridinolina e excreção de NTX $^{(32)}$. Quadro laboratorial semelhante foi recentemente descrito em mulheres com osteoporose idiopática, as quais não apresentavam deficiência de $\mathrm{IGFl}^{(31)}$. Entretanto, muitos pacientes com osteoporose idiopática não apresentam aumento nos marcadores bioquímicos de reabsorção, mas apenas menor capacidade de formação óssea, por vezes associada à hipercalciúria ${ }^{(33)}$. A presença de hipercalciúria também foi descrita em mulheres com osteoporose idiopática, com história familiar de hipercalciúria ${ }^{(34)}$.

\section{DIAGNÓSTICO POR HISTOMORFOMETRIA ÓSSEA}

Histomorfometrias ósseas de pacientes com osteoporose idiopática apresentam alteração da formação óssea $(33,35)$. Reed et $a^{(35)}$ estudaram 18 homens e 12 mulheres com osteoporose idiopática, mostrando redução do volume ósseo, do volume osteóide e da superfície osteóide. A concentração sérica de IGFl nesses pacientes era menor que a de 33 pacientes saudáveis controle. Além disso, houve correlação significativa entre o IGFl sérico e superfície osteoblástica, superfície de mineralização e taxa de formação óssea. Outros autores confirmaram a associação positiva entre o IGFl medido na matriz óssea e parâmetros histomorfométricos de formação e reabsorção óssea, assim como o volume ósseo (22).

O IGFl liberado pela matriz óssea durante a reabsorção parece participar do acoplamento na formação óssea, e uma diminuição dos níveis de IGFl intra-ósseo pode resultar num desequilíbrio da remodelação e contribuir para a perda óssea gradual que ocorre principalmente com o envelhecimento. Também na osteoporose idiopática a redução da concentração de IGFl pode ter um papel na etiologia da doença. Entretanto, nem todos os pacientes com osteoporose idiopática apresentam níveis séricos de IGFl baixos (25), não sendo o IGFl sérico bom preditor da remodelação óssea e do volume ósseo. 
A biópsia óssea é a forma mais precisa de diagnosticar outras doenças, como a osteogenesis imperfecta, aferir o processo de remodelação óssea e quantificar a massa óssea, mas é uma técnica invasiva, incômoda e dispendiosa. Estas restrições levam à aplicação, mesmo em casos de osteoporose idiopática, de avaliações não-invasivas da massa óssea e do seu metabolismo pelas dosagens do marcadores bioquímicos de remodelação óssea.

\section{TRATAMENTO}

Em tese, o achado de reabsorção óssea aumentada aponta para o emprego de drogas anti-reabsortivas, como os bisfosfonatos. Nos casos sem alteração dos marcadores bioquímicos de reabsorção óssea, em que se supõe haver menor capacidade de formação óssea, o emprego da terapia anabólica parece melhor justificado. Apesar de fazer sentido do ponto de vista teórico, não há evidência sólida na literatura que justifique basear a escolha da terapia medicamentosa nos marcadores de remodelação. Aparentemente, a eficácia antifratura das drogas anti-reabsortivas e dos fármacos osteoanabólicos independe do status da remodelação óssea. Assim, descrevemos abaixo as alternativas terapêuticas da osteoporose idiopática.

\section{MEDICAMENTOS ANTI-REABSORTIVOS:BISFOSFONATOS}

Embora na osteoporose idiopática geralmente se encontre uma histomorfometria com baixa remodelação, até há pouco tempo os bisfosfonatos constituíam um dos únicos medicamentos aprovados para osteoporose. Por ocasionar uma diminuição da perda óssea, favorece o ganho de massa óssea com a terapia prolongada, embora haja tendência a se atingir um plateau a partir do segundo ou terceiro ano de uso da droga. Esta resposta positiva dos bisfosfonatos, confirmada em casos de osteoporose idiopática ${ }^{(36)}$, pode ser justificada pelo achado de reabsorção óssea excedendo a formação óssea ${ }^{(32)}$.Além da sua ação anti-reabsortiva, verificou-se in vitro que os bisfosfonatos previnem a apoptose dos osteoblastos e osteócitos ${ }^{(37)}$, o que acrescenta uma justificativa bastante atraente para o seu emprego na osteoporose idiopática.

\section{TERAPIA ANABÓLICA}

Com a sugestão de um possível defeito na formação óssea pelos achados histomorfométricos na osteoporose idiopática a terapia anabólica passou a ser considerada promissora $^{(38)}$.

\section{FLUORETO}

Foi o primeiro agente anabólico usado para tratamento de osteoporose pós-menopausa, não aprovado pela Food and Drug Administration (FDA) por não modificar a incidência de fraturas vertebrais e até aumentar o risco de fraturas não vertebrais (em doses diárias de $75 \mathrm{mg} /$ dia de fluoreto de sódio), apesar do incremento na densidade óssea. Mais recentemente Ringe et a ${ }^{(39)}$ demonstraram efeitos positivos com baixa dose intermitente por três anos com uma formulação diferente do fluoreto, o monofluorofosfato, em homens com osteoporose idiopática. Em função de resultados conflitantes, o FDA não aprovou qualquer preparação de fluoreto para prevenção ou tratamento de osteoporose.

\section{$G H$}

As experiências com pacientes com deficiência de GH sugerem que a reposição com hGH pode acarretar aumento dos marcadores de remodelação óssea e perda óssea em menos de 12 meses. Entretanto, resulta em aumento da DMO após mais de 12 meses, o que diminui o risco de fraturas $^{(40)}$. Um período curto de uso do hGH, como sete dias, já é capaz de causar estimulação do metabolismo ósseo que perdura por semanas ${ }^{(41)}$. Estudos experimentais em animais demonstram que o hGH aumenta a espessura cortical e, conseqüentemente, o tamanho ósseo ${ }^{(42)}$.

Gillberg et a ${ }^{433}$ avaliaram o efeito do tratamento com hGH por dois anos, usado de forma contínua -1,2 U/dia $(0,4 \mathrm{mg})$ e intermitente $-2,4 \mathrm{U} / \mathrm{dia}(0,8 \mathrm{mg})$ por duas semanas, trimestralmente - na remodelação óssea, densidade óssea e tamanho ósseo em 29 homens com osteoporose idiopática. Houve ganho da DMO em coluna lombar e corpo inteiro com possível incremento por pelo menos um ano pós-tratamento, não havendo qualquer efeito no tamanho do osso. Os autores sugerem que o hGH possa ser considerado como opção terapêutica no tratamento da osteoporose idiopática. Entretanto, a ausência de um grupo controle limita as conclusões quanto à eficácia do tratamento.

IGFI

Com o achado de baixos níveis séricos de IGFl em homens com osteoporose idiopática, acreditou-se inicialmente que a sua reposição resolveria a questão. Em 1996, Johansson et $\mathrm{al}^{\mathrm{I}^{44)}}$ testaram o efeito de curto prazo de uso de hGH e IGF-1 em 12 homens com osteoporose idiopática: houve aumento dos marcadores de remodelação, mas a densidade óssea não foi avaliada. Em mulheres idosas, a administração de IGF1 recombinante $(30 \mathrm{mg} / \mathrm{kg} /$ dia $)$ por 
um ano resultou em aumento significativo do IGFl, mas redução de $20 \%$ da OPG sérica $(p<0.05)$, assim favorecendo a reabsorção óssea ${ }^{(26)}$. Estudos de curto prazo em mulheres jovens com anorexia nervosa sugerem que as mesmas doses de IGFl recombinante favorecem a formação ${ }^{(38)}$. Assim, além do alto custo, ainda não está definida a utilidade do IGFI recombinante no tratamento da osteoporose.

\section{PTH}

A constatação de que a exposição intermitente ao PTH estimula a formação óssea, ao contrário da exposição contínua (hiperparatireoidismo) que resulta em aumento da reabsorção óssea, o PTH recombinante foi estudado e aprovado como terapia anabólica na osteoporose ${ }^{(45)}$. Em culturas de células ósseas, o PTH intermitente (0,1-10nM) estimula diretamente a produção de colágeno tipo 1 e proteínas não-colágenas pelos osteoblastos. $\mathrm{O} \mathrm{PTH}$ ainda bloqueia a apoptose dos osteoblastos. O efeito osteoindutor do PTH anabólico é complexo e envolve múltiplas vias de sinalização celular, ligadas a peptídeos de sinalização que afetam a transcrição gênica em osteoblastos. A expressão de IGFl no microambiente ósseo exerce papel importante neste efeito do PTH intermitente ${ }^{(46)}$.

\section{REFERÊNCIAS}

1. Heshmati HM, Khosla S: Idiopathic osteoporosis: a heterogeneous entity. Ann Med Interne (Paris) 149: 77-81, 1998.

2. Baudoin C, Cohen-Solal ME, Beaudreuil J, Vernejoul MC: Genetic and environmental factors affect bone density variances of families of men and women with osteoporosis. J Clin Endocrinol Metab 87: 2053-9, 2002.

3. Koller DL, Ecous MJ, Morin PA et al: Genome screen for QTLS contributing to normal variation in bone mineral density and osteoporosis. J Clin Endocrinol Metab 85: 3116-20, 2000.

4. Ferrari S, Rizzoli R, Slosman D, Bonjour JP: Familial resemblance for bone mineral mass is expressed before puberty. J Clin Endocrinol Metab 83: 358-61, 1998.

5. Matkovic V, Jelic T, Wardlaw GM, et al: Timing of peak bone mass in caucasian females and its implication for the prevention of osteoporosis. J Clin Invest 93: 799-808, 1994.

6. Slemenda CW, Christian JC, Williams CJ, Norton JA, Johnston CC: Genetic determinants of bone mass in adult women: a reevaluation of the twin model and the potential importance of gene interaction on heritability estimates. J Bone Miner Res 6: $561-7,1991$.
Em humanos, o PTH é administrado em doses diárias de $20 \mu \mathrm{g}$, por via subcutânea, e sua meia vida muito rápida garante o efeito intermitente. Em homens com osteoporose idiopática, o PTH recombinante ${ }^{(1-34)}$ aumentou a densidade mineral óssea em coluna lombar ${ }^{(47)}$ e colo femural ${ }^{(48,49)}$. Vale mencionar que o tratamento prévio com bisfosfonato pode limitar o incremento na densidade mineral óssea obtido com PTH recombinante ${ }^{(50)}$. Por outro lado, o emprego do bisfosfonato após a interrupção da teriparatida parece conveniente, otimizando o ganho de densidade mineral óssea em coluna lombar ${ }^{(51)}$.

\section{CONSIDERAÇÕES FINAIS}

Quando se detecta osteoporose em um paciente jovem, deve-se exaustivamente investigar possíveis causas de osteopenia/osteoporose avaliando todos os fatores potencialmente envolvidos no pico de massa óssea e na perda óssea, buscando intervenção precoce a fim de garantir qualidade óssea e menor risco de fraturas. Afastadas todas as causas potencialmente conhecidas e firmado o diagnóstico de osteoporose idiopática, o uso de bisfosfonatos e/ou a terapia anabólica com GH ou PTH podem ser considerados.

7. Peacock M, Turner CH, Econs MJ, Foroud T: Genetics of osteoporosis. Endocr Rev 23: 303-26, 2002.

8. Rivadeneira F, Houwing-Duistermaat J, Pols HA et al: Insulinlike-growth-factor 1 (IGFl) gene promoter polymorphism and the risk of fracture in the elderly: the Rotterdam study. J Bone Miner Res 17(suppl1): S177, 2002.

9. Rosen CJ, Kurland ES, Vereault D et al: Association between serum insulin-growth-factor 1 (IGF1) and a simple repeat in IGFl gene: implications for genetic studies of bone mineral density. J Clin Endocrinol Metab 83: 2286-90, 1998.

10. Cooper GS, Umbach DM: Are vitamin D receptor polymorphisms associated with bone mineral density? A metanalysis. J Bone Miner Res 11: 1841-9, 1996.

11. Sainz J, Van Tornout JM, Loro L et al: Vitamin D receptor gene polymorphisms and bone density in prepubertal American girls of Mexican descent. N Engl J Med 337: 77-82, 1997.

12. Dawson-Hughes B, Harris SS, Finneran S: Calcium absorption on high and low calcium intakes in relation to vitamin $\mathrm{D}$ receptor genotype. J Clin Endocrinol Metab 80: 3657-61, 1995.

13. Sainz J, Van Tornout JM, Sayre J, Kaufman F, Gilsanz V: Association of collagen type I $\alpha$ l gene polymorphism with bone density in early childhood. J Clin Endocrinol Metab 84: 
853-5, 1999.

14. Peris $\mathrm{P}$, Alvarez L, Oriola J et al: Collagen type I $\alpha$ l gene polymorphism in idiopathic osteoporosis in men. Rheumatology 39: 1222-5, 2000.

15. Lorentzon M, Lorentzon R, Backstrom T, Nordstrom P: Estrogen receptor gene polymorphism, but not estradiol levels, is related to bone density in healthy adolescent boys: a crosssectional and longitudinal study. J Clin Endocrinol Metab 84: 4597-601, 1999.

16. Mizunuma $\mathrm{H}$, Hosoi $\mathrm{T}$, Okano $\mathrm{H}$, et al: Estrogen receptor gene polymorphism and bone mineral density at the lumbar spine of pre and post menopausal women. Bone 21: 379-83, 1997.

17. Uitterlinden AG, Arp PP, Paeper BW et al: Polymorphisms in the sclerosteosis/van Buchem disease gene (SOST) region are associated with bone-mineral density in elderly whites. Am J Hum Genet 75: 1032-45, 2004.

18. Langdahl BL, Vestergaard P, Abrahamsen B, Tofteng CL, Kolthoff N, Mosekilde L: Polymorphisms in the promoter of the osteoprotegerin gene are associated with reduced perimenopausal bone mass. J Bone Miner Res 17 (suppl 1): S423, 2002.

19. Holmes SJ, Economou G, Whitehouse RW, Adams JE, Shalet SM: Reduced bone mineral density in patients with adult onset growth hormone deficiency. J Clin Endocrinol Metab 78: 66974, 1994.

20. Rosen CJ, Pollak MF: IGFl and aging: a new perspective for a new century. Trends Endocrinol Metab 10: 136-42, 1999.

21. Kurland ES, Chan FKW, Rosen CJ, Bilezikian JP: Normal growth hormone secretory reserve in men with idiopathic osteoporosis and reduced circulating levels of insulin-like growth factor-I. J Clin Endocrinol Metab 83: 2576-9, 1998.

22. Ljunghal S, Johannsson AG, Burman P, Kampe O, Lindh E, Karlsson FA: Low plasma levels of IGF1 in male patients with idiopathic osteoporosis. J Intern Med 232: 59-64, 1992.

23. Canalis E: Growth factors, bone metabolism and metabolic bone diseases. Endocrinologist 6: 89-94, 1996.

24. Hill PA, Tumber A, Meikle MC: Multiple extracellular signals promote osteoblast survival and apoptosis. Endocrinology 138 : 3849-58, 1997.

25. Khosla S: Editorial: Idiopathic osteoporosis-is the osteoblast to blame? J Clin Endocrinol Metab 82: 2792-4, 1997.

26. Rubin J, Ackert-Bicknell CL, Zhu L et al: IGFl regulates osteoprotegerin (OPG) and receptor activator of nuclear factorkappa ligand in vitro and OPG in vivo. J Clin Endocrinol Metab 87: 4273-9, 2002.

27. Kanis J A: Assessment of fracture risk. Who should be screened? In: Favus MJ. Primer on the Metabolic Bone Diseases and Disorders of Mineral Metabolism. $5^{\text {th }}$ ed, Washington DC, The American Society for Bone and Mineral Research, 316-23, 2003.

28. Harper KD, Weber TJ: Secondary osteoporosis: diagnostic considerations. Endocrinol Metab Clin North Am 27: 325-48, 1998.

29. Lewiecki EM, Watts NB, McClung MR et al: Official Positions of the International Society for Clinical Densitometry. J Clin Endocrinol Metab 89: 3651-5, 2004.
30. Cohen-Solal ME Omouri M, Baudoin C, Kuntz D, de Vernejoul MC: Bone mass in middle-aged osteoporotic men and relatives: familial effect. J Bone Miner Res 13: 1909-14, 1998.

31. Rubin MR, Schussheim DH, Kulak CA et al: Idiopathic osteoporosis in premenopausal women. Osteoporos Int 16: 526-33, 2005.

32. Pietschmann P, Kudlacek S, Grisar J et al: Bone turnover markers and sex hormones in men with idiopathic osteoporosis. Eur J Clin Invest 31: 444-51, 2001.

33. Zerwekh JE, Sakhaee K, Breslau NA, Gottschalk F, Pak CYC: Impaired bone formation in male idiopathic osteoporosis: further reduction in the presence of concomitant hypercalciuria. Osteoporosis Int 2: 128-34, 1992.

34. Peris P, Guanabens N, Martinez de Osaba MJ et al: Clinical characteristics and etiologic factors of premenopausal osteoporosis in a group of Spanish women. Semin Arthritis Rheum 32: 64-70, 2002.

35. Reed BY, Zerwekh JE, Sakhaee K, Breslau NA, Gorrschalk F, Pak CYC: Serum IGF1 is low and correlated with osteoblastic surface in idiophatic osteoporosis. J Bone Miner Res 10: 121824, 1995.

36. Weber TJ, Drezner MK: Effect of alendronate on bone mineral density in male idiopathic osteoporosis. Metabolism 50: 912-5, 2001.

37. Plotkin LI, Weinstein RS, Parfitt AM, Roberson PK, Manolagass C, Bellido T: Prevention of osteocyte and osteoblast apoptosis by bisphosphonates and calcitonin. J Bone Miner Res 104: 1363-74, 1999.

38. Rosen CJ, Bilezikian JP: Anabolic therapy for osteoporosis. J Clin Endocrinol Metab 86: 957-64, 2001.

39. Ringe JD, Dorst A, Kipshoven C, Rovati LC, Setnikar I: Avoidance of vertebral fractures in men with idiophatic osteoporosis by a three-year therapy with calcium and low-dose intermittent monofluorophosphate. Osteoporos Int 8: 47-52, 1998.

40. Nilsson AG: Effects of growth hormone replacement therapy on bone markers and bone mineral density in growth hormonedeficient adults. Horm Res 54: 52-7, 2000.

41. Brixen K, Kassem M, Nielse HK, Loft AG, Flyvbjerg A, Mosekilde L: Short-term treatment with growth hormone stimulates osteoblastic and osteoclastic activity in osteopenic postmenopausal women: a dose response study. J Bone Miner Res10: 1865-74, 1995.

42. Andreassen TT, Melsen F, Oxlund H: The influence of growth hormone on cancellous and cortical bone of vertebral body in aged rats. J Bone Miner Res 11: 1094-102, 1996.

43. Gillberg P, Mallmin H, Petren-Mallmin M, Lunghall S, Nilsson AG: Two years of treatment with recombinant human growth hormone increases bone mineral density in men with idiopathic osteoporosis. J Clin Endocrinol Metab 87: 4900-6, 2002.

44. Johansson AG, Lindh E, Blum WF, Kollerup G, Sorensen OH, Ljunghall S: Effects of growth hormone and insulin-like growth factor I in men with idiopathic osteoporosis. J Clin Endocrinol Metab 81: 44-8, 1996.

45. Tashiian AH, Chabner BA: Clinical safety of recombinant human parathyroid hormone (1-34) in the treatment of osteoporosis in postmenopausal women and men. J Bone Miner Res 17: 1151- 
61, 2002.

46. Canalis E Centrella M, Burch W, Mc Carthy TL: Insulin-like growth factor I mediates selective anabolic effects of parathyroid hormone in bone cultures. J Clin Invest 83: 60-S, 1989.

47. Orwoll ES, Scheele WH, Paul S, Adami S, Syversen U, DiezPerez A: Brief therapy with recombinant human parathyroid hormone (1-34) increases lumbar spine bone mineral density in men with idiopathic or hypogonadal osteoporosis. J Bone Miner Res 16: S1-S221, 2001.

48. Kurland ES, Cosman F, Mc Mahon DJ, Rosen CJ, Lindsay R, Bilezikian JP: Parathyroid hormone as a therapy for osteoporosis in men: effects on bone mineral density and bone markers. J Clin
Endocrinol Metab 85: 3069-76, 2000.

49. Orwoll ES, Scheele W, Paul S, et al: The effect of teriparatide [human parathyroid hormone (1-34)] therapy on bone density in men with osteoporosis. J Bone Miner Res 18: 9-17, 2003.

50. Filkelstein JS, Hayes A, Rao A, Neer RM: Effects of parathyroid hormone, alendronate, or both on bone density in osteoporotic men. J Bone Miner Res 17(Suppl 1): S127, 2002.

51. Kurland ES, Heller SL, Diamond B, McMahon DJ, Cosman F, Bilezikian JP: The importance of bisphosphonate therapy in maintaining bone mass in men after therapy with teriparatide [human parathyroid hormone (1-34)]. Osteoporos Int 15: 992 $7,2004$. 